Check for updates

Cite this: RSC Adv., 2019, 9, 21931

\title{
Highly effective carbon-supported gold-ionic liquid catalyst for acetylene hydrochlorination
}

\begin{abstract}
Xueyan Qi, (D)*ab Weifeng Chen ${ }^{c}$ and Jinli Zhang (D)*b
The sulfur-containing ionic liquid (IL) trimethylsulfonium iodide $\left(\mathrm{C}_{3} \mathrm{H}_{9} \mathrm{SI}\right)$ was used to synthesize an efficient non-mercuric catalyst with $\mathrm{HAuCl}_{4} \cdot 4 \mathrm{H}_{2} \mathrm{O}$ as a precursor and spherical active carbon (SAC) as a support. Various $\mathrm{Au}-\mathrm{IL} / \mathrm{SAC}$ catalysts were synthesized using the incipient wetness impregnation technique and applied to acetylene hydrochlorination. The $0.3 \% \mathrm{Au}-\mathrm{IL} / \mathrm{SAC}$ catalyst showed the best catalytic performance, with an acetylene conversion of $90 \%$ at a temperature of $170{ }^{\circ} \mathrm{C}$ and gas hourly space velocity (GHSV) of $360 \mathrm{~h}^{-1}$ using water as the solvent. The catalyst also displayed excellent long-term stability: $\mathrm{C}_{2} \mathrm{H}_{2}$ conversion was maintained at $97 \%$ for up to $200 \mathrm{~h}\left(T=170{ }^{\circ} \mathrm{C}, \mathrm{GHSV}=90 \mathrm{~h}^{-1}\right)$. Brunauer-Emmett-Teller surface area, thermogravimetric analysis, temperature programmed desorption, X-ray diffraction, transmission electron microscopy, and X-ray photoelectron spectroscopy results together showed that the $\mathrm{C}_{3} \mathrm{H}_{9} \mathrm{SI}$ additive significantly improved the dispersion of Au species and inhibited coke deposition on the catalyst surface during the acetylene hydrochlorination reaction. The superior activity and stability of the Au-IL/SAC catalyst make it a green catalyst for the industrial application of acetylene hydrochlorination.
\end{abstract}

Received 30th May 2019

Accepted 3rd July 2019

DOI: $10.1039 / c 9 r a 04082 j$

rsc.li/rsc-advances researchers have been investigating non-precious metals, and even nonmetallic materials as catalysts of the reaction. ${ }^{\mathbf{1 5 - 2 0}}$ While they are less expensive than the Au-based catalysts, their catalytic activities are also much lower. Therefore, the study of catalysts with gold as the active component was also the main focus for acetylene hydrochlorination. In recent years, gold complex catalysts such as the Au-GSH complex and $\mathrm{AuPPh}_{3} \mathrm{Cl}$ complex have been designed. ${ }^{21-23}$ Note that sulfur-containing ligands have been shown by Hutchings and co-workers to stabilize $\mathrm{Au}(\mathrm{I})$ catalysts. ${ }^{23}$ The stable cationic gold was shown to be present in the form of gold-sulfur bonds and to be highly dispersed in the catalyst. They also illustrated that even sulfurcontaining ligands dissociated, and the presence of the sulfur moiety may serve to immobilize/anchor the Au and help prevent reduction and sintering of Au. The gold complex catalyst exhibited superefficient catalytic activity and stability even when the amount of gold loaded was reduced to $0.1 \mathrm{wt} \%$ at 500 $\mathrm{h}^{-1}$.

Recently, the use of ionic liquids (ILs) as green solvents and catalysts has been receiving increasing attention. ${ }^{24-26}$ It has been shown that IL films could-due to their excellent solubility, low volatility and high thermal stability-be used to dissolve transition-metal complexes. As a thin film on the catalyst surface, an IL provides a homogeneous solvent environment that stabilizes the metal cation and accelerates mass transfer for the transition metal catalyst. ${ }^{27}$ Zhao et al. reported that the $\mathrm{Au}(\mathrm{III})$-IL/AC catalyst with 1-propyl-3-methylimidazolium chloride as the ionic liquid for acetylene hydrochlorination exhibited a relatively high catalytic performance of about $77.1 \%$ for
${ }^{a}$ College of Materials Science and Engineering, Hebei University of Engineering, Handan 056038, Hebei, PR China. E-mail: qixueyan001@163.com

${ }^{b}$ School of Chemical Engineering and Technology, Tianjin University, Tianjin 300072, PR China.E-mail: zhangjinli@tju.edu.cn

'The 718th Research Institute of China Shipbuilding Heavy Industry Corporation, Handan 056027, Hebei, PR China. E-mail: chen228@tju.edu.cn 
$\mathrm{C}_{2} \mathrm{H}_{2}$ conversion..$^{28} \mathrm{Li}$ et al. investigated $\mathrm{Ru}-\mathrm{IL} / \mathrm{AC}$ catalysts using the supported ionic liquid phase (SILP) technique for acetylene hydrochlorination, and the best catalyst was 1\% Ru@15\% TPPB/AC, which showed excellent acetylene conversion of 99.7\% under the reaction conditions of $170{ }^{\circ} \mathrm{C}$, GHSV $\left(\mathrm{C}_{2} \mathrm{H}_{2}\right)$ of $360 \mathrm{~h}^{-1}$, and $\mathrm{V}_{(\mathrm{HCl})} / \mathrm{V}_{\left(\mathrm{C}_{2} \mathrm{H}_{2}\right)}=1.5 .{ }^{27}$ All of these results showed that the IL could significantly stabilize the metal oxidation state and prevent the formation of agglomerate. On the other hand, it is worth mentioning that the oxidizing aqua regia or hydrochloric acid is often used as a solvent to ensure that the catalyst contains a relatively high number of cationic Au species during the preparation process and the reaction. However, aqua regia or hydrochloric acid are corrosive and may hence be harmful to exposed workers and equipment. Some of these catalysts when used with water as the solvent show decreased catalytic activity because the catalysts contain in this case a relatively high amount of $\mathrm{Au}^{0}$. Considering the excellent catalytic performance and preparation methods of IL catalysts, it is necessary to continue to investigate producing more efficient ILs, convenient preparation methods, and environmentally friendly gold-based catalysts for acetylene hydrochlorination.

In the current work, sulfur-bearing ILs were adopted with water as the solvent to prepare Au-IL/spherical activated carbon (SAC) catalysts using the incipient wetness impregnation method, and these catalysts were assessed for acetylene hydrochlorination. The trimethylsulfonium iodide additive provided the sulfur atom that increased the electron density of the $\mathrm{Au}^{3+}$ center via the transfer of the lone pair of electrons from the sulfur atom to the $\mathrm{Au}^{3+}$ center. On the other hand, there was an electrostatic interaction of cationic gold with the iodine anion. $\mathrm{Au}^{3+}$ species have been shown to serve as electron donors in the $\mathrm{HCl}$ adsorption process, ${ }^{29}$ and it was, therefore, most likely that this feature promoted the ability of Au-IL/SAC catalysts to adsorb a relatively high amount of hydrogen chloride and stabilize cationic gold during the reaction. The Au-IL/AC catalyst exhibited high catalytic activity, specifically with $90 \%$ acetylene conversion, $38 \%$ more than that of the catalyst without IL. The results indicated that the IL additive could substantially improve the dispersion of gold species, enhance the adsorption of $\mathrm{HCl}$ and inhibit the coke deposition.

\section{Experimental}

\subsection{Materials}

$\mathrm{HAuCl}_{4} \cdot 4 \mathrm{H}_{2} \mathrm{O}$ (Au content $\geq 47.8 \%$ ) was purchased from Alfa Aesar; trimethylsulfonium iodide $\left(\mathrm{C}_{3} \mathrm{H}_{9} \mathrm{SI}\right.$, purity $\left.\geq 98 \%\right)$ was supplied by Tianjin Xiensi Bio-Chem Technology Development Co., Ltd., and spherical activated carbon (SAC, neutral, pitchbased, 20-40 mesh) was purchased from ShangHai Carbosino Material Co., Ltd. All of the other materials and chemicals were commercially available and were used without further purification.

\subsection{Catalyst preparation}

$\mathrm{Au}-\mathrm{IL} / \mathrm{SAC}$ catalysts were prepared via the incipient wetness impregnation method. An $\mathrm{HAuCl}_{4}$ aqueous solution $(10 \mathrm{ml}$,
$0.00121 \mathrm{~mol} \mathrm{~L}^{-1}$ or $0.00363 \mathrm{~mol} \mathrm{~L}^{-1}$ ) was added dropwise to $5 \mathrm{~g}$ of SAC under stirring, and then steeped for $12 \mathrm{~h}$ at room temperature, followed by the desiccation of this mixture in a water bath at $60{ }^{\circ} \mathrm{C}$ for $10 \mathrm{~h}$. Then, an aqueous solution of $\mathrm{C}_{3} \mathrm{H}_{9} \mathrm{SI}(10 \mathrm{ml})$ was added to the above mixture under constant stirring. The mixture was set aside for $10 \mathrm{~h}$, evaporated in a steam bath, and then dried at $120{ }^{\circ} \mathrm{C}$ for $12 \mathrm{~h}$. The resultant catalyst was named $\mathrm{Au}-10 \% \mathrm{IL} / \mathrm{SAC}$. For comparison, the $\mathrm{Au} /$ SAC catalyst was also prepared under the same conditions as described above. Additionally, the dip order of gold and $\mathrm{C}_{3} \mathrm{H}_{9} \mathrm{SI}$ was changed to obtain the $10 \% \mathrm{IL}-\mathrm{Au} / \mathrm{SAC}$ catalyst. Other goldbased catalysts with various relative amounts of $\mathrm{C}_{3} \mathrm{H}_{9} \mathrm{SI}$ from $5 \mathrm{wt} \%$ to $30 \mathrm{wt} \%$ were prepared. Au loading in all of the $\mathrm{Au}-$ based catalysts was fixed at $0.1 \mathrm{wt} \%$ or $0.3 \mathrm{wt} \%$.

\subsection{Catalytic performance tests}

The catalytic performance test was carried out in a fixed-bed micro-reactor (i.d. of $10 \mathrm{~mm}$ ). A CKW-1100 temperature controller (Chaoyang Automation Instrument Factory, Beijing, China) was used to control the temperature of the reaction. Acetylene (gas, 99.9\% purity) was treated using a silica-gel desiccant to remove trace impurities, and hydrogen chloride (gas, 99.9\% purity) was passed through 5A molecular sieves for drying. Nitrogen was purged into the reactor to remove the air and water in the system before the reaction. The catalyst was activated by hydrogen chloride gas with a flow rate of 25 $\mathrm{mL} \min ^{-1}$ for $30 \mathrm{~min}$. Hydrogen chloride and acetylene with

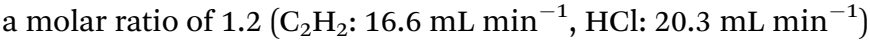
were introduced into the reactor containing $3 \mathrm{~mL}$ of the catalyst until the reaction temperature reached $170{ }^{\circ} \mathrm{C}$. A $360 \mathrm{~h}^{-1} \mathrm{C}_{2} \mathrm{H}_{2}$ gas hourly space velocity (GHSV) was achieved by controlling the calibrated mass flow meters. The reactor effluent stream was passed through an absorption bottle containing an aqueous solution of $\mathrm{NaOH}$ to remove superfluous $\mathrm{HCl}$ and then the gas mixture was analyzed online by using a BeiFen $3420 \mathrm{~A}$ gas chromatograph.

\subsection{Catalyst characterizations}

The BET pore structure and specific surface areas were investigated by using a Quantachrome Autosorb Automated Gas Sorption System (Quantachrome Instruments, USA). The samples were degassed at $160^{\circ} \mathrm{C}$ for $4 \mathrm{~h}$, and then analyzed via liquid nitrogen adsorption at $-196{ }^{\circ} \mathrm{C}$.

Thermogravimetric analysis (TGA) was carried out using a TG-DTA 2 thermal analyzer (METTLER TOLEDO, Switzerland) under an air atmosphere with a flow rate of $60 \mathrm{~mL} \mathrm{~min}^{-1}$. The temperature was increased from $35{ }^{\circ} \mathrm{C}$ to $900{ }^{\circ} \mathrm{C}$ with a heating rate of $10^{\circ} \mathrm{C} \mathrm{min}{ }^{-1}$.

$\mathrm{X}$-ray diffraction (XRD) patterns were collected on a D8-Focus diffractometer using $\mathrm{Cu} \mathrm{K} \alpha$ radiation $(\lambda=1.5406 \AA)$ at a scanning rate of $5{ }^{\circ} \mathrm{C} \min ^{-1}$, with $2 \theta$ ranging from $10^{\circ}$ to $90^{\circ}$.

Temperature-programmed desorption (TPD) experiments were performed using an AutoChem BET TPR/TPD (Quantachrome Instruments AMI-90). First, the catalysts (150 mg) were treated with $\mathrm{C}_{2} \mathrm{H}_{2}$ and $\mathrm{HCl}$ gas for $4 \mathrm{~h}$ at the reaction temperature in the reactor. The catalysts, after having adsorbed these 
species, were treated with $\mathrm{He}$ gas at $30{ }^{\circ} \mathrm{C}$ for $30 \mathrm{~min}$, and then the temperature was increased from $30{ }^{\circ} \mathrm{C}$ to $900{ }^{\circ} \mathrm{C}$ under an He gas atmosphere. For the $\mathrm{C}_{2} \mathrm{H}_{3} \mathrm{Cl}-\mathrm{TPD}$, the $\mathrm{C}_{2} \mathrm{H}_{3} \mathrm{Cl}$ gas was adsorbed by the samples on a TPD instrument for $1 \mathrm{~h}$ at $170{ }^{\circ} \mathrm{C}$ and then the desorption procedure was carried out as described above.

Transmission electron microscopy (TEM) was carried out using a JEM 2100F electron microscope. The catalyst in powder form was first dispersed in ethanol and the resulting suspension was added dropwise onto carbon-film-coated copper TEM grids, which were then used to obtain the images.

X-ray photoelectron spectroscopy (XPS) data were obtained using a Thermo ESCALAB 250Xl (Thermo Fisher Scientific, USA), with a monochromatic Al K $\alpha$ X-ray source (225 W). The binding energies were adjusted by referencing the $\mathrm{C}(1 \mathrm{~s})$ level at $284.4 \mathrm{eV}$.

\section{Results and discussion}

\subsection{Performance of Au-based catalysts}

Fig. 1(a) shows the catalytic performance of the Au-10\% IL/SAC catalyst, and the corresponding performances of SAC, IL/SAC, $\mathrm{Au} / \mathrm{SAC}$ and $10 \% \mathrm{IL}-\mathrm{Au} / \mathrm{SAC}$ materials for comparison. The acetylene conversion of SAC was initially $25 \%$ and then decreased to $22 \%$ in $24 \mathrm{~h}$. $10 \%$ IL/SAC exhibited higher activity than did SAC at the beginning of reaction, but nearly the same activity as did SAC after $24 \mathrm{~h}$. These results showed that the individual IL/SAC sample contributed very little to the activity. For the pristine Au/SAC $(0.1 \mathrm{wt} \% \mathrm{Au})$ catalyst, the acetylene conversion decreased from $80 \%$ to $47 \%$ after $24 \mathrm{~h}$ of reaction at $170{ }^{\circ} \mathrm{C}$. The $\mathrm{Au}-10 \% \mathrm{IL} / \mathrm{SAC}$ showed the highest catalytic activity of $84 \%$ and only a reduction of $6 \%$ after 24 hours of reaction. It should be noted that the Au-based catalysts displayed a significant increase of $\mathrm{C}_{2} \mathrm{H}_{2}$ conversion after adding the IL. The $10 \%$ IL-Au/SAC catalyst showed the lowest initial activity of all the Au-based catalysts, with a conversion of $74 \%$ at $3 \mathrm{~h}$ and $48 \%$ at $24 \mathrm{~h}$. While the conversion of the $10 \%$ IL-Au/SAC was higher than that of $\mathrm{Au} / \mathrm{SAC}$ within the first 20 hours, it showed poor stability. For loadings of $\mathrm{C}_{3} \mathrm{H}_{9} \mathrm{SI}$ between $5 \%$ and $30 \%$, i.e., when using Au-5\% IL/SAC, Au-10\% IL/SAC, Au-20\% IL/SAC and Au-30\% IL/SAC catalysts, acetylene conversions of $79 \%, 79 \%$, $84 \%$ and $74 \%$ were achieved, and decreased to $76 \%, 77 \%, 82 \%$ and $70 \%$, respectively, after the 24 hours of the reaction (Fig. 1(b)). These results indicated that the $\mathrm{C}_{3} \mathrm{H}_{9} \mathrm{SI}$ additive can be used to improve the activity of Au-based catalysts, and in our experiments the $\mathrm{Au}-20 \% \mathrm{IL} / \mathrm{SAC}$ catalyst showed the best activity of all of the catalysts.

After adopting the optimal dipping order and the optimal $\mathrm{C}_{3} \mathrm{H}_{9} \mathrm{SI}$ loading level, the $\mathrm{Au}$ loading was increased from $0.1 \mathrm{wt} \%$ to $0.3 \mathrm{wt} \%$ in order to obtain more convincing characterization results. The $\mathrm{C}_{2} \mathrm{H}_{2}$ conversions of these catalysts are shown in Fig. 2. The $0.3 \% \mathrm{Au} / \mathrm{SAC}$ catalyst showed an acetylene conversion of $65 \%$ after $3 \mathrm{~h}$. The optimum acetylene conversion over $0.3 \% \mathrm{Au}-\mathrm{IL} / \mathrm{SAC}$ catalyst was $90 \%$ with a steady $100 \%$ selectivity for VCM. The $\mathrm{C}_{2} \mathrm{H}_{2}$ conversion of the $0.3 \%$ Au-IL/SAC catalyst was $35 \%$ higher than that of the sample without ionic liquid after 24 hours. These results suggested that the IL additive can markedly improve the activity and selectivity of gold catalysts for acetylene hydrochlorination.

\subsection{Catalyst characterizations}

3.2.1 BET results. The pore structure parameters of the catalysts were investigated by carrying out low-temperature $\mathrm{N}_{2}$ adsorption/desorption experiments. As listed in Table 1, the SAC support showed type-I isotherms and the bare SAC displayed a specific surface area of $1149 \mathrm{~m}^{2} \mathrm{~g}^{-1}$ and a total pore volume of $0.661 \mathrm{~cm}^{3} \mathrm{~g}^{-1}$. After the loading of gold species and IL, the surface area and total pore volume of the SAC decreased, indicating that the carrier channel was blocked by the active gold species or the $\mathrm{C}_{3} \mathrm{H}_{9} \mathrm{SI} .{ }^{30}$ Comparing the data indicated that the used catalysts exhibited lower surface areas and total pore volume than did the fresh catalyst after $24 \mathrm{~h}$ of the reaction. For the used $0.3 \% \mathrm{Au} / \mathrm{SAC}$ catalyst, the surface area decreased by about $10 \%$, from an initial value of $956 \mathrm{~m}^{2} \mathrm{~g}^{-1}$ to $860 \mathrm{~m}^{2} \mathrm{~g}^{-1}$. Likewise, the surface area of the used $0.3 \% \mathrm{Au}-\mathrm{IL} / \mathrm{SAC}$ catalysts decreased by about $7 \%$. The particular variations are shown in Table 1 . For the $0.3 \% \mathrm{Au} / \mathrm{SAC}$ catalyst, the amplitude of
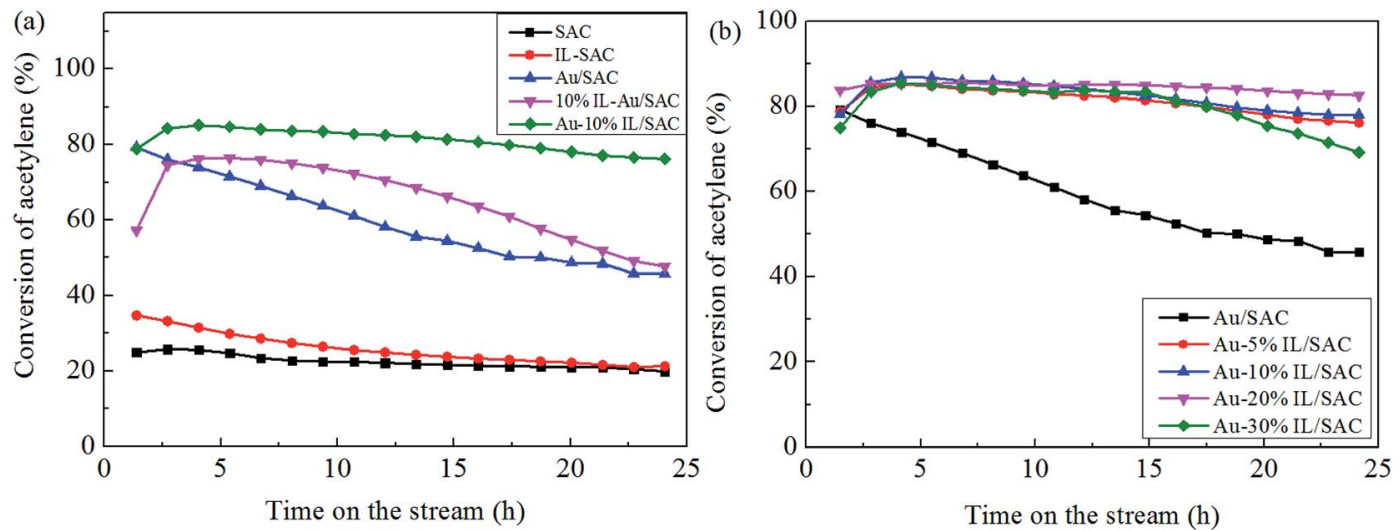

Fig. 1 The acetylene conversions of Au-IL catalysts with different dipping orders (a) and different ionic liquid loading levels (b). Reaction conditions: $T=170{ }^{\circ} \mathrm{C}, \mathrm{C}_{2} \mathrm{H}_{2}$ gas hourly space velocity $(\mathrm{GHSV})=180 \mathrm{~h}^{-1}$, feed volume ratio $\mathrm{V}_{(\mathrm{HCl})} / \mathrm{V}_{\left(\mathrm{C}_{2} \mathrm{H}_{2}\right)}=1.2,0.1 \mathrm{wt} \%$ Au. 

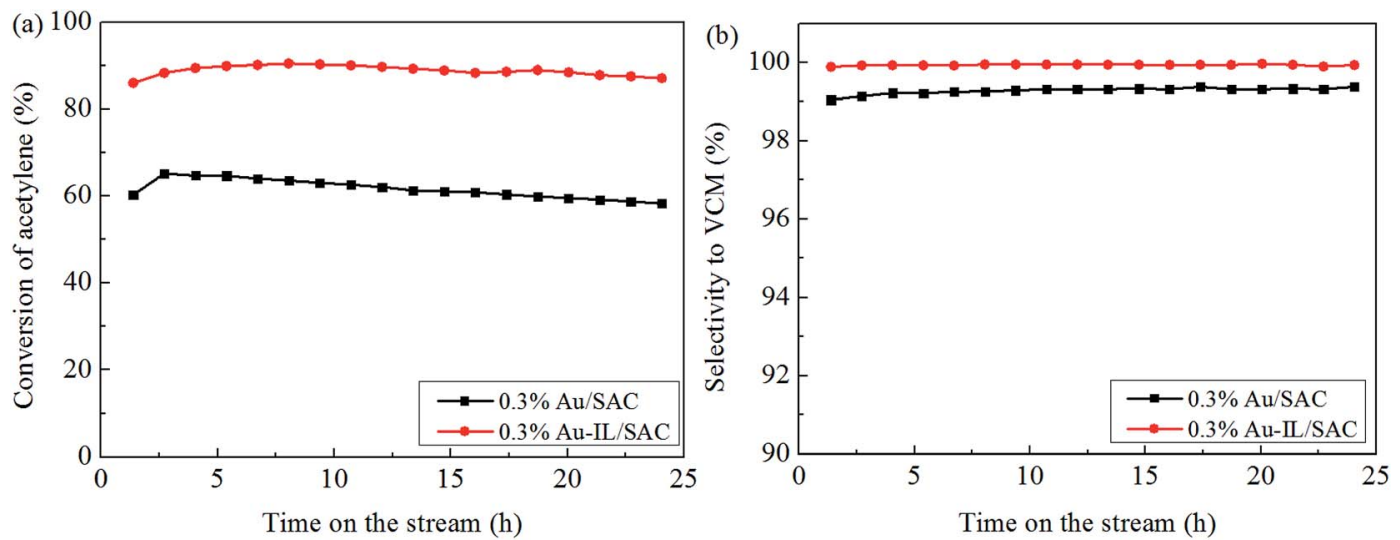

Fig. 2 The acetylene conversion and selectivity for VCM of $0.3 \% \mathrm{Au} / \mathrm{SAC}$ and $0.3 \% \mathrm{Au}-\mathrm{IL} / \mathrm{SAC}$ catalysts. Reaction conditions: $T=170{ }^{\circ} \mathrm{C}, \mathrm{C}_{2} \mathrm{H}_{2}$ gas hourly space velocity $(\mathrm{GHSV})=360 \mathrm{~h}^{-1}$, feed volume ratio $\mathrm{V}_{(\mathrm{HCl})} / \mathrm{V}_{\left(\mathrm{C}_{2} \mathrm{H}_{2}\right)}=1.2,0.3 \mathrm{wt} \% \mathrm{Au}$.

Table 1 Pore structure parameters of the fresh and used Au-based catalysts

\begin{tabular}{|c|c|c|c|c|c|c|}
\hline \multirow[b]{2}{*}{ Catalyst } & \multicolumn{2}{|c|}{$S_{\mathrm{BET}}\left(\mathrm{m}^{2} \mathrm{~g}^{-1}\right)$} & \multicolumn{2}{|c|}{$\begin{array}{l}\text { Total pore } \\
\text { volume } \\
\left(\mathrm{cm}^{3} \mathrm{~g}^{-1}\right)\end{array}$} & \multirow[b]{2}{*}{$\Delta S_{\mathrm{BET}} \%$} & \multirow[b]{2}{*}{$\Delta V \%$} \\
\hline & Fresh & Used & Fresh & Used & & \\
\hline SAC & 1149 & 1055 & 0.661 & 0.612 & 8.2 & 7.4 \\
\hline $0.3 \% \mathrm{Au} / \mathrm{SAC}$ & 956 & 860 & 0.464 & 0.413 & 10 & 11 \\
\hline $0.3 \% \mathrm{Au}-\mathrm{IL} / \mathrm{SAC}$ & 825 & 768 & 0.402 & 0.377 & 7 & 6.2 \\
\hline
\end{tabular}

variation of $S_{\mathrm{BET}}\left(\Delta S_{\mathrm{BET}}\right)$ and that of $V(\Delta V)$ were measured to be $10 \%$ and $11 \%$. The $0.3 \%$ Au-IL/SAC catalyst showed lower surface area and pore volume variations than did $0.3 \% \mathrm{Au} / \mathrm{SAC}$, specifically values of $7 \%$ and $6.2 \%$ for $\Delta S_{\mathrm{BET}}$ and $\Delta V$, respectively. These results, combined with the trend of the variations of the activity and BET data for the catalysts, indicated that the variation was probably due to catalyst sintering or carbon deposition during the reaction. ${ }^{31}$

3.2.2 Coking deposition analysis. TGA was performed to measure the amount of coke deposited over the $0.3 \% \mathrm{Au} / \mathrm{SAC}$ and $0.3 \% \mathrm{Au}-\mathrm{IL} / \mathrm{SAC}$ catalysts. As seen in Fig. 3 and Table 2, all of the catalysts showed a slight weight loss as the temperature was increased up to $150{ }^{\circ} \mathrm{C}$, attributed to water desorption from the surfaces of catalysts. The fresh $0.3 \% \mathrm{Au} /$ SAC catalyst displayed a weight loss of about $3.4 \%$ as the temperature was increased from $150-556{ }^{\circ} \mathrm{C}$. In this same temperature range, the used $0.3 \% \mathrm{Au} / \mathrm{SAC}$ catalyst underwent a more marked weight loss (7.5\%), attributed to the burning of deposited carbon and carbon-containing groups during the acetylene hydrochlorination reaction. The TGA curves of the fresh and used $0.3 \% \mathrm{Au}-\mathrm{IL} / \mathrm{SAC}$ catalysts showed mass losses of, respectively, $4.6 \%$ and $6.7 \%$ as the temperature was increased from $150{ }^{\circ} \mathrm{C}$ to $556{ }^{\circ} \mathrm{C}$. Both the fresh and used catalysts showed rapid weight losses after $556^{\circ} \mathrm{C}$, attributed to the combustion of activated carbon.

Coke deposition was calculated using the previously described method, ${ }^{\mathbf{1 2}}$ and the computed results are listed in Table 2. The relative amount of deposited coke was $4.3 \%$ for the $0.3 \% \mathrm{Au} / \mathrm{SAC}$ catalyst and $2.1 \%$ for the $0.3 \% \mathrm{Au}-\mathrm{IL} / \mathrm{SAC}$ catalyst after $24 \mathrm{~h}$ of reaction. The trend here was similar to that for the BET results, as coke deposition in general causes losses of both surface area and pore volume. Therefore, we concluded that the $\mathrm{C}_{3} \mathrm{H}_{9} \mathrm{SI}$ additive inhibited the formation of coke deposits, and that this inhibition enhanced the catalytic activity.

3.2.3 Adsorption properties of the fresh catalysts. TPD profiles were plotted to explore the adsorption properties of the
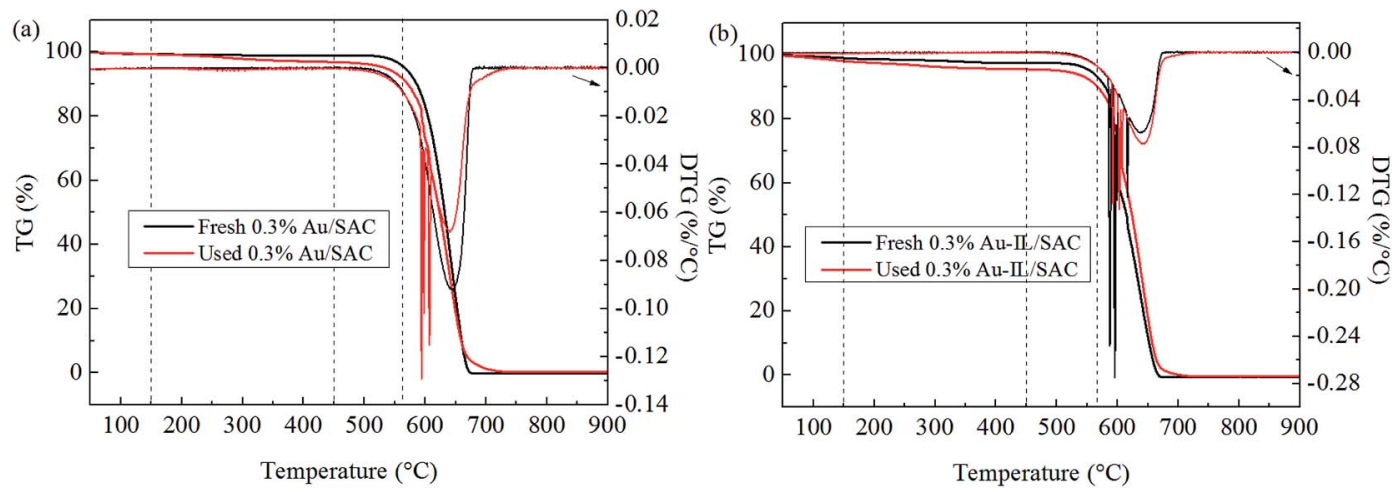

Fig. 3 TG and DTG curves of the fresh and used 0.3\% Au/SAC and 0.3\% Au-IL/SAC catalysts. 
Table 2 Carbon deposition on the 0.3\% Au/SAC and 0.3\% Au-IL/SAC catalysts

\begin{tabular}{ll}
\hline Catalysts & $\begin{array}{l}\text { Amount of carbon } \\
\text { deposition }(\%)\end{array}$ \\
\hline $0.3 \% \mathrm{Au} / \mathrm{SAC}$ & 4.1 \\
$0.3 \% \mathrm{Au}-\mathrm{IL} / \mathrm{SAC}$ & 2.1
\end{tabular}

reactants and the product of the fresh catalysts. Generally, the peak area represents adsorption ability and desorption temperature reflects adsorption strength. Fig. 4(a) displays the $\mathrm{C}_{2} \mathrm{H}_{2}$-TPD profiles of the fresh $0.3 \% \mathrm{Au} / \mathrm{SAC}$ and $0.3 \% \mathrm{Au}-\mathrm{IL} / \mathrm{SAC}$ catalysts. Both of the catalysts yielded an obvious desorption peak of acetylene in the temperature range $100-450{ }^{\circ} \mathrm{C}$. For the $0.3 \% \mathrm{Au} / \mathrm{SAC}$ catalyst, the desorption temperature was $210^{\circ} \mathrm{C}$, a value $10{ }^{\circ} \mathrm{C}$ lower than that for the $0.3 \%$ Au-IL/SAC sample. The desorption area of acetylene for the $0.3 \% \mathrm{Au}-\mathrm{IL} / \mathrm{SAC}$ catalyst was greater than that for the fresh $0.3 \% \mathrm{Au} / \mathrm{SAC}$ sample. These results taken together indicated that the $\mathrm{C}_{3} \mathrm{H}_{9} \mathrm{SI}$ additive enhanced the ability of the sample to adsorb $\mathrm{C}_{2} \mathrm{H}_{2}$. The HClTPD profiles are shown in Fig. 4(b). All of the catalysts yielded two $\mathrm{HCl}$ desorption peaks, which may have been due to physical adsorption at the low-temperature range and chemical adsorption at the high-temperature range. The $\mathrm{HCl}$ desorption area of the $0.3 \% \mathrm{Au}-\mathrm{IL} / \mathrm{SAC}$ catalyst was considerably larger than that of $0.3 \% \mathrm{Au} / \mathrm{SAC}$ sample, indicating that the $0.3 \% \mathrm{Au}-\mathrm{IL} / \mathrm{SAC}$ catalyst strongly adsorbed $\mathrm{HCl}$. As for the product VCM, the result was found to be opposite that of the $\mathrm{HCl}$ reactant. As shown in Fig. 4(c), the two catalysts showed markedly different VCM desorption areas. The VCM area of the $0.3 \%$ Au-IL/SAC catalyst was measured to be less than that of the $0.3 \% \mathrm{Au} / \mathrm{SAC}$ catalyst. These results suggested a relatively rapid diffusion of the products out of the catalyst channel, hence lessening the occurrence of carbon deposition. In summary, the addition of $\mathrm{C}_{3} \mathrm{H}_{9} \mathrm{SI}$ to the catalyst not only enhanced the adsorption of the reactants, especially $\mathrm{HCl}$, but also promoted desorption of the VCM product. The TPD results combined with the DTA results provided powerful evidence that adding $\mathrm{C}_{3} \mathrm{H}_{9} \mathrm{SI}$ to the Au-based catalyst can inhibit the deposition of coke during the reaction.

3.2.4 Valence change of the active component. Fig. 5 shows the XRD patterns of the fresh and used Au-based catalysts. Apart from the amorphous diffraction peaks and the typical coal peaks of the SAC, a diffraction peak at $38.08^{\circ}$ was detected for the fresh $0.3 \% \mathrm{Au} / \mathrm{SAC}$ catalyst and was assigned to the (111) planes of metallic $\mathrm{Au}^{0}$. This result indicated that the preparation process led to the reduction of $\mathrm{Au}^{3+}$ to $\mathrm{Au}^{0}$. For the used $0.3 \% \mathrm{Au} / \mathrm{SAC}$ catalyst, the intensity of the Au reflection at $38.08^{\circ}$ was observed to be even more intense, indicating additional reduction from $\mathrm{Au}^{3+}$ to $\mathrm{Au}^{0}$ during the reaction. Besides the amorphous diffraction peaks of carbon, no discernible reflection was detected for the fresh $0.3 \% \mathrm{Au}-\mathrm{IL} / \mathrm{SAC}$ catalysts, not even in the used sample, indicating the high dispersion of active species. These results clearly indicated that the addition of IL suppressed the reduction of $\mathrm{Au}^{3+}$ to $\mathrm{Au}^{0}$ and improved the dispersion of active species, not only in the preparation process but also during the reaction.
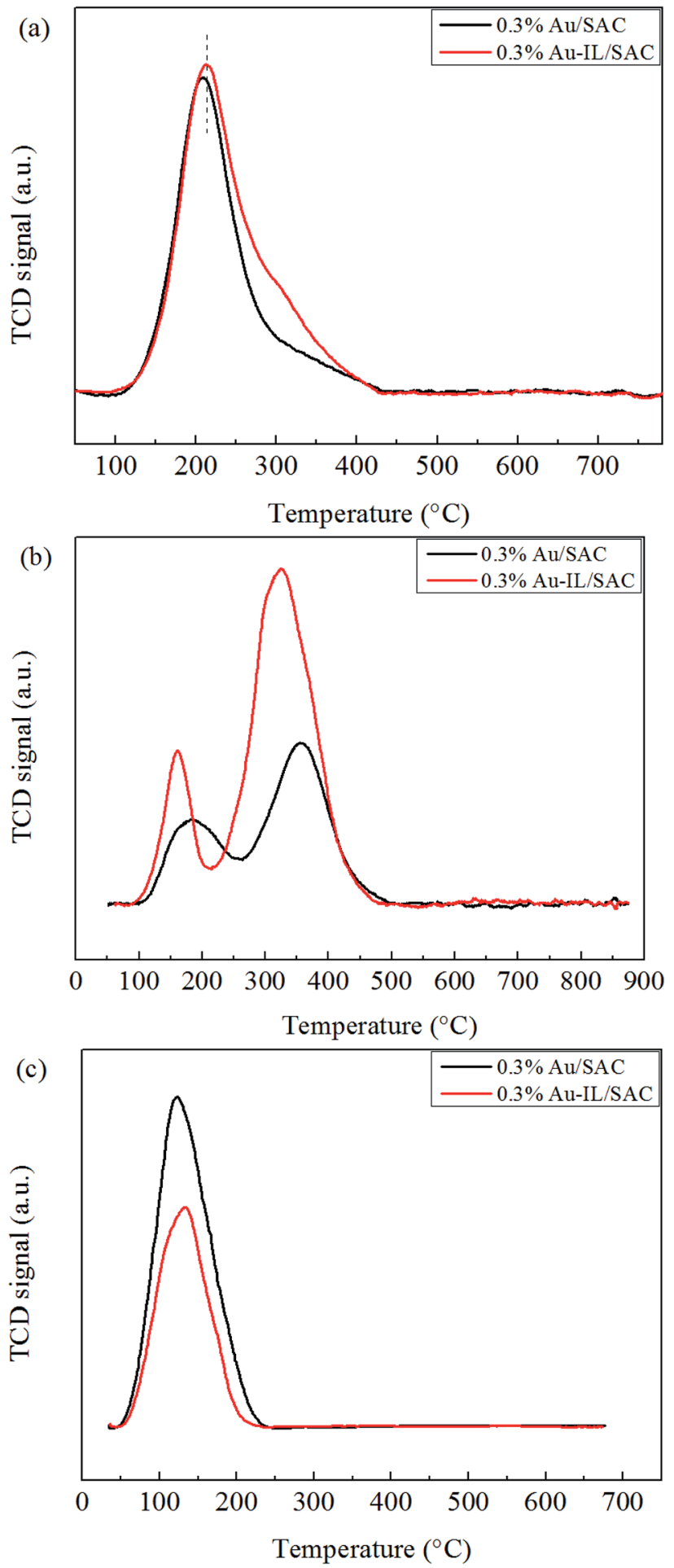

Fig. 4 TPD profiles of the fresh $0.3 \% \mathrm{Au} / \mathrm{SAC}$ and $0.3 \% \mathrm{Au}-\mathrm{IL} / \mathrm{SAC}$ catalysts for (a) $\mathrm{C}_{2} \mathrm{H}_{2}-\mathrm{TPD}$, (b) HCl-TPD, and (c) VCM-TPD.

TEM images were obtained to gain more information about the particle size and dispersion of Au species, as shown in Fig. 6. The average particle dimensions were measured from these images to be $3.0 \mathrm{~nm}$ and $3.3 \mathrm{~nm}$ for the fresh and used $0.3 \% \mathrm{Au} / \mathrm{SAC}$ catalysts. The pitch-based activated carbon has better catalytic activity than do 


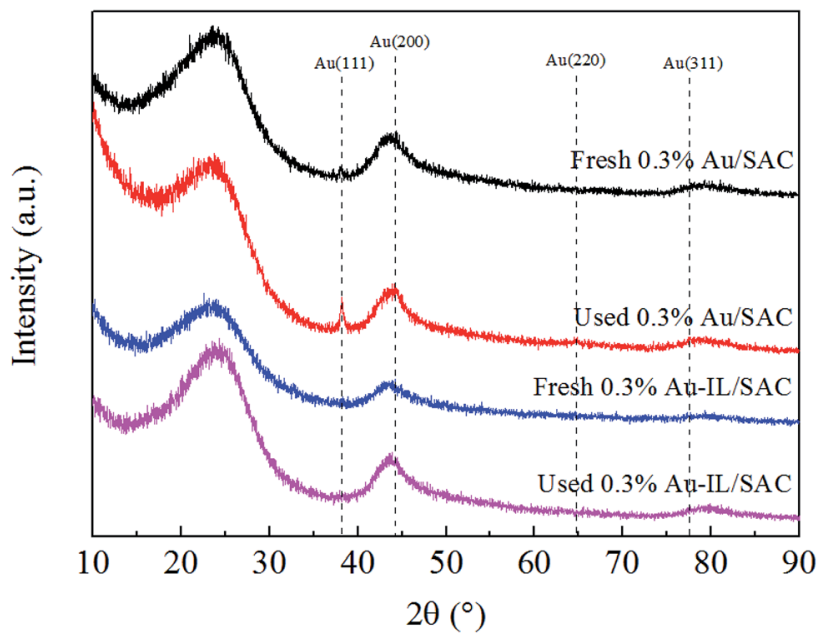

Fig. 5 XRD patterns of $0.3 \% \mathrm{Au} / \mathrm{SAC}$ and $0.3 \% \mathrm{Au}$-IL/SAC catalysts.

coconut shell-based activated carbon and coal-based activated carbon. Therefore, after short reaction times, the gold particle dimensions were less than $4 \mathrm{~nm}$ whether fresh or used $0.3 \% \mathrm{Au} / \mathrm{SAC}$ catalyst was deployed. For the fresh and used $0.3 \% \mathrm{Au}-\mathrm{IL} / \mathrm{SAC}$ catalysts, the particle dimensions were $1.2 \mathrm{~nm}$ and $1.3 \mathrm{~nm}$, respectively. It was reasonable to conclude that the addition of IL made the gold species highly dispersed on the surface of the support, effectively preventing the reduction of $\mathrm{Au}^{3+}$ to $\mathrm{Au}^{0}$.

XPS spectra were acquired to monitor the valence state and relative amount of gold species for the fresh and used Au-based catalysts. Typical XPS spectra in the region of the $\mathrm{Au} 4 \mathrm{f}$ orbital for $0.3 \% \mathrm{Au} / \mathrm{SAC}$ and $0.3 \% \mathrm{Au}-\mathrm{IL} / \mathrm{SAC}$ are shown in Fig. 7. These data indicated that both $\mathrm{Au}^{3+}$ and $\mathrm{Au}^{0}$ coexisted in the fresh and used catalysts.

Table 3 lists the binding energies and the relative amounts of Au species. For the fresh $0.3 \% \mathrm{Au} / \mathrm{SAC}$, peaks at binding energy values of $86.5 \mathrm{eV}$ and $84.3 \mathrm{eV}$ were observed, and were attributed to $\mathrm{Au}^{3+}$ and $\mathrm{Au}^{0}$, respectively. According to the XPS data of the fresh catalysts, the presence of the $\mathrm{C}_{3} \mathrm{H}_{9} \mathrm{SI}$ additive reduced the binding energy of $\mathrm{Au}^{3+}$ by $0.1 \mathrm{eV}$, while that of $\mathrm{Au}^{0}$ increased by $0.1 \mathrm{eV}$. This result indicated that electron transfer indeed occurred and that
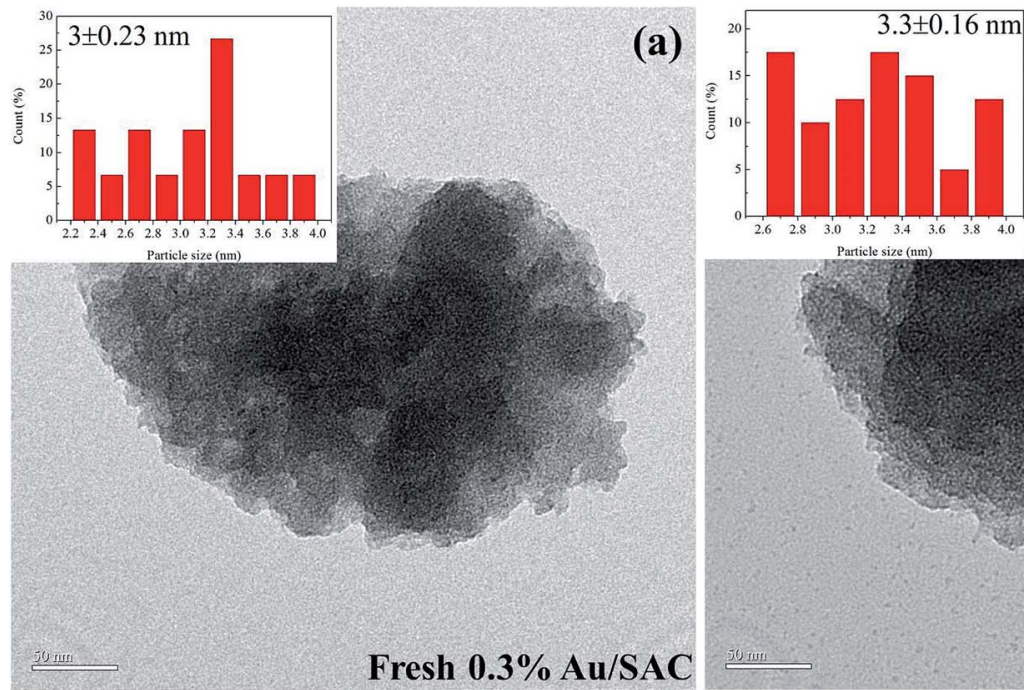

(b)

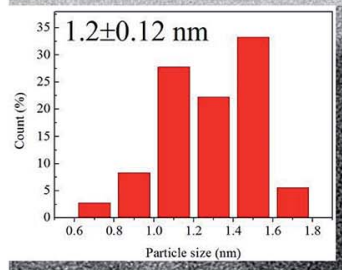

(c)
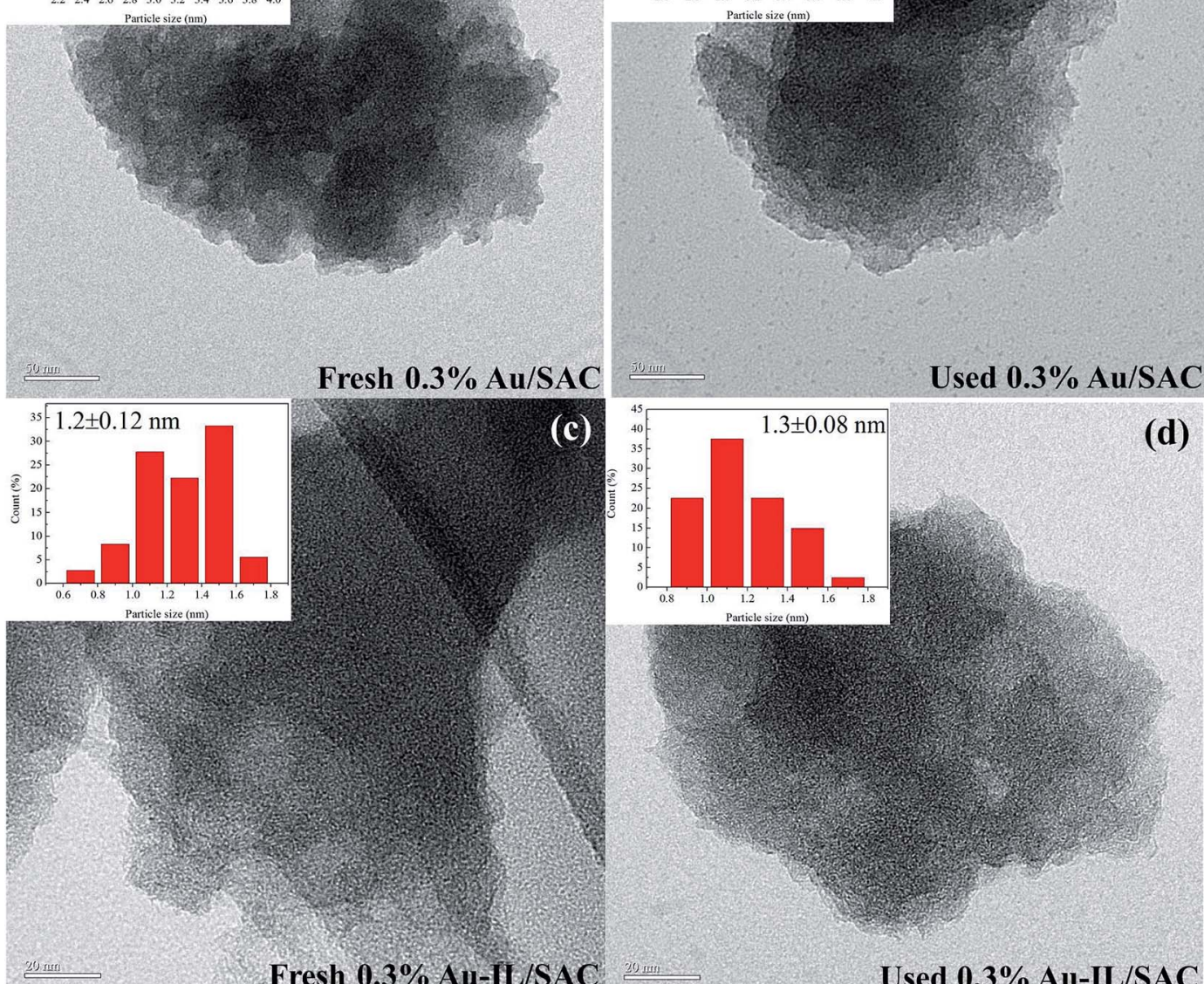

Fresh $0.3 \%$ Au- IL/SAC

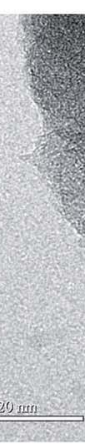

(d)

Fig. 6 TEM images of the fresh and used $0.3 \% \mathrm{Au} / \mathrm{SAC}$ and $0.3 \% \mathrm{Au}-\mathrm{IL} / \mathrm{SAC}$ catalysts. 

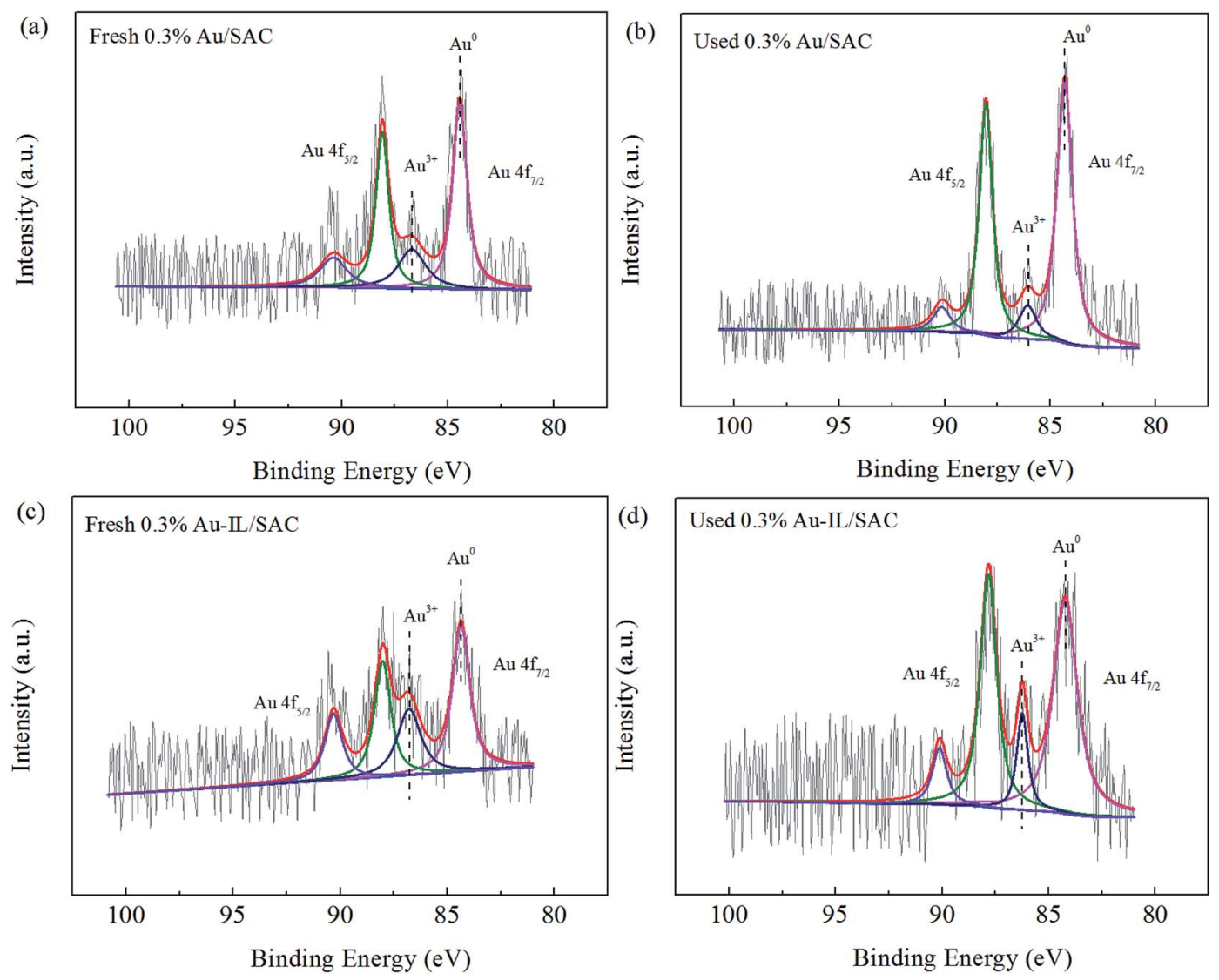

Fig. 7 High-resolution XPS spectra in the Au $4 f$ region for the fresh and used 0.3\% Au/SAC and 0.3\% Au-IL/SAC catalysts.

Table 3 Relative amounts and binding energies of gold species in $0.3 \% \mathrm{Au} / \mathrm{SAC}$ and $0.3 \% \mathrm{Au}-\mathrm{IL} / \mathrm{SAC}$ catalysts

\begin{tabular}{|c|c|c|c|c|}
\hline \multirow[b]{2}{*}{ Catalyst } & \multicolumn{2}{|c|}{$\mathrm{Au}$ species (\%) } & \multicolumn{2}{|c|}{$\begin{array}{l}\text { Binding } \\
\text { energies }(\mathrm{eV})\end{array}$} \\
\hline & $\mathrm{Au}^{3+}$ & $\mathrm{Au}^{0}$ & $\mathrm{Au}^{3+}$ & $\mathrm{Au}^{0}$ \\
\hline Fresh $0.3 \% \mathrm{Au} / \mathrm{SAC}$ & 28.7 & 71.3 & 86.5 & 84.3 \\
\hline Used $0.3 \% \mathrm{Au} / \mathrm{SAC}$ & 12.5 & 87.5 & 86.3 & 84.3 \\
\hline Fresh $0.3 \%$ Au-IL/SAC & 38 & 62 & 86.4 & 84.4 \\
\hline Used $0.3 \%$ Au-IL/SAC & 25.5 & 74.5 & 86.3 & 84.3 \\
\hline
\end{tabular}

there was a strong interaction between the gold species and $\mathrm{C}_{3} \mathrm{H}_{9} \mathrm{SI}$ additive. For the fresh $0.3 \% \mathrm{Au} / \mathrm{SAC}$ and $0.3 \% \mathrm{Au}-\mathrm{IL} /$ SAC catalysts, the relative amounts of the active component $\mathrm{Au}^{3+}$ were $28.7 \%$ and $38.0 \%$, respectively. The used $0.3 \% \mathrm{Au} /$ SAC catalyst had a relatively large amount $(87.5 \%)$ of metallic $\mathrm{Au}^{0}$ and hence low amount (12.5\%) of $\mathrm{Au}^{3+}$ species. However, the $0.3 \% \mathrm{Au}-\mathrm{IL} / \mathrm{SAC}$ catalyst showed fewer $\mathrm{Au}^{3+}$ ions reduced to $\mathrm{Au}^{0}$ than did $0.3 \% \mathrm{Au} / \mathrm{SAC}$ after the reaction. This result showed that the IL additive suppressed the reduction of $\mathrm{Au}^{3+}$ to $\mathrm{Au}^{0}$ during the reaction and improved the catalytic activity, in accordance with the results of the XRD and TEM analyses.

3.2.5 Long-term stability testing. The Au-IL/SAC catalyst was subjected to a long-term stability testing, specifically for more than $200 \mathrm{~h}$, under the reaction conditions of $170{ }^{\circ} \mathrm{C}$, the GHSV $\left(\mathrm{C}_{2} \mathrm{H}_{2}\right)$ of $90 \mathrm{~h}^{-1}$ and $\mathrm{V}_{\mathrm{HCl}} / \mathrm{V}_{\mathrm{C}_{2} \mathrm{H}_{2}}=1.2$. As shown in Fig. 8, the acetylene conversion decreased just from $97 \%$ to $95 \%$ after more than $200 \mathrm{~h}$ of reaction. This result provided evidence for the suitability of the Au-IL/SAC catalyst for long-term tests and industrial production needs.

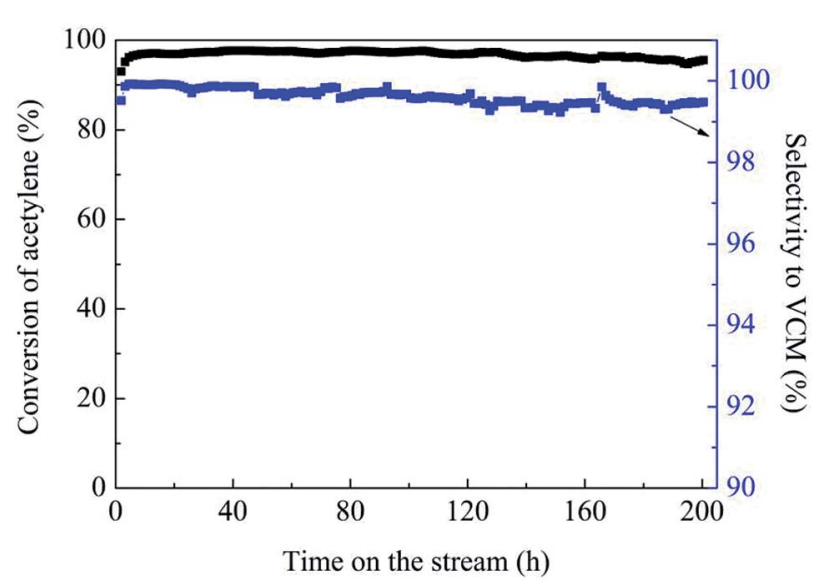

Fig. 8 Long-term stability testing of the $0.3 \%$ Au-IL/SAC catalyst. Reaction conditions: temperature $(T)=170{ }^{\circ} \mathrm{C}, \mathrm{C}_{2} \mathrm{H}_{2}$ gas hourly space velocity $(\mathrm{GHSV})=90 \mathrm{~h}^{-1}$, feed volume ratio $\mathrm{V}_{(\mathrm{HCl})} / \mathrm{V}_{\left(\mathrm{C}_{2} \mathrm{H}_{2}\right)}=1.2,0.3 \mathrm{wt} \%$ $\mathrm{Au}$. 


\section{Conclusions}

In summary, Au-IL/SAC catalysts were prepared and assessed for the acetylene hydrochlorination reaction. Compared to the $0.3 \% \mathrm{Au} / \mathrm{SAC}$ catalyst, the $0.3 \% \mathrm{Au}-\mathrm{IL} / \mathrm{SAC}$ catalyst exhibited obviously better catalytic performance. Under the conditions of temperature $=170{ }^{\circ} \mathrm{C}, \mathrm{V}_{(\mathrm{HCl})} / \mathrm{V}_{\left(\mathrm{C}_{2} \mathrm{H}_{2}\right)}=1.2$, and GHSV $\left(\mathrm{C}_{2} \mathrm{H}_{2}\right)=$ $360 \mathrm{~h}^{-1}$, the $0.3 \%$ Au-IL/SAC catalyst showed the best performance, with an acetylene conversion of $90 \%$ and the selectivity for VCM of $100 \%$. The characterizations indicated the ability of the IL additive to effectively inhibit carbon deposition of the catalyst, simultaneously improve the dispersion of gold species, and enhance the amounts of acetylene and especially hydrogen chloride adsorbed on the catalyst. In addition, the interaction between gold and IL was indicated to stabilize the high valence state of the Au species and endow the catalyst with long-term stability. The optimized catalyst thus has the potential for use in industrial production due to its advantageous low cost, ease of preparation, and non-polluting character.

\section{Conflicts of interest}

There are no conflicts to declare.

\section{Acknowledgements}

We gratefully acknowledge the financial support of the Major State Basic Research Development Program (No. 2012CB720302) and NSFC (21176174).

\section{References}

1 G. Malta, S. J. Freakley, S. A. Kondrat and G. J. Hutchings, Chem. Commun., 2017, 53, 11733-11746.

2 G. J. Hutchings, J. Catal., 1985, 96, 292.

3 G. J. Hutchings and D. T. Grady, Appl. Catal., 1985, 17, 155. 4 B. Nkosi, M. D. Adams, N. J. Coville and G. J. Hutchings, J. Catal., 1991, 128, 378-386.

5 M. Conte, A. F. Carley, G. Attard, A. A. Herzing, C. J. Kiely and G. J. Hutchings, J. Catal., 2008, 257, 190-198.

6 M. Conte, A. F. Carley, C. Heirene, D. J. Willock, P. Johnston, A. A. Herzing, C. J. Kiely and G. J. Hutchings, J. Catal., 2007, 250, 231-239.

7 M. Conte, A. F. Carley and G. J. Hutchings, Catal. Lett., 2008, 124, 165-167.
8 M. Conte, C. J. Davies, D. J. Morgan, T. E. Davies, A. F. Carley, P. Johnston and G. J. Hutchings, Catal. Sci. Technol., 2013, 3, 128.

9 S. Wang, B. Shen and Q. Song, Catal. Lett., 2010, 134, 102.

10 H. Zhang, W. Li, X. Li, W. Zhao, J. Gu, X. Qi, Y. Dong, B. Dai and J. Zhang, Catal. Sci. Technol., 2015, 5, 1870.

11 K. Zhou, W. Wang, Z. Zhao, G. Luo, J. T. Miller, M. Wong and F. Wei, ACS Catal., 2014, 4, 3112.

12 G. Li, W. Li and J. Zhang, Catal. Sci. Technol., 2016, 6, 3230.

13 Y. Pu, J. Zhang, X. Wang, H. Zhang, L. Yu, Y. Dong and W. Li, Catal. Sci. Technol., 2014, 4, 4426.

14 Y. Dong, H. Zhang, W. Li, M. Sun, C. Guo and J. Zhang, J. Ind. Eng. Chem., 2016, 35, 177.

15 X. Li, Y. Wang, L. Kang, M. Zhu and B. Dai, J. Catal., 2014, 311, 288-294.

16 X. Li, X. Pan, L. Yu, P. Ren, X. Wu, L. Sun, F. Jiao and X. Bao, Nat. Commun., 2014, 5, 3688-3694.

17 K. Zhou, J. Si, J. Jia, J. Huang, J. Zhou, G. Luo and F. Wei, ChemSusChem, 2014, 4, 7766-7769.

18 K. Zhou, B. Li, Q. Zhang, J. Huang, G. Tian, J. Jia, M. Zhan, G. Luo, D. Su and F. Wei, ChemSusChem, 2014, 7, 723-728.

19 J. Zhao, Y. Yu, X. Xu, S. Di, B. Wang, H. Xu, J. Ni, L. Guo, Z. Pan and X. Li, Appl. Catal., B, 2017, 206, 175-183.

20 B. Dai, K. Chen, Y. Wang, L. Kang and M. Zhu, ACS Catal., 2015, 5, 2541-2547.

21 X. Qi, W. Li, J. Gu, C. Guo and J. Zhang, RSC Adv., 2016, 6, 105110-105118.

22 Y. Dong, W. Li, Z. Yan and J. Zhang, Catal. Sci. Technol., 2016, 6, 7946-7955.

23 P. Johnston, N. Carthey and G. J. Hutchings, J. Am. Chem. Soc., 2015, 137, 14548-14557.

24 J. F. Wishart, Energy Environ. Sci., 2009, 2, 956.

25 L. Han, S. W. Park and D. W. Park, Energy Environ. Sci., 2009, 2, 1286.

26 J. Hu, Q. Yang, L. Yang, Z. Zhang, B. Su, Z. Bao, Q. Ren, H. Xing and S. Dai, ACS Catal., 2015, 5, 6724-6731.

27 S. Shang, W. Zhao, Y. Wang, X. Li, J. Zhang, Y. Han and W. Li, ACS Catal., 2017, 7, 3510-3520.

28 J. Zhao, S. Gu, X. Xu, T. Zhang, Y. Yu, X. Di, J. Ni, Z. Pan and X. Li, Catal. Sci. Technol., 2016, 6, 3263-3270.

29 J. Zhao, T. Zhang, X. Di, J. Xu, J. Xu, F. Feng, J. Ni and X. Li, RSC Adv., 2015, 5, 6925-6931.

30 H. Zhang, B. Dai, X. Wang, W. Li, Y. Han, J. Gu and J. Zhang, Green Chem., 2013, 15, 829.

31 B. Nkosi, N. J. Coville, G. J. Hutchings, M. D. Adams, J. Friedl and F. E. Wagner, J. Catal., 1991, 128, 366. 